\title{
Effect of Therapeutic Plasma Exchange on Plasma Constituents in Neurointensive Care Unit Patients: A Retrospective Study
}

\author{
Deepti Srinivas ${ }^{1}$ Kamath Sriganesh ${ }^{2}$ Dhritiman Chakrabarti ${ }^{2, \odot ~ P a v i t h r a ~ V e n k a t e s w a r a n ~}{ }^{3}$
}

1Department of Neuroanaesthesia and Neurocritical Care, Apollo Hospitals, Bangalore, Karnataka, India

${ }^{2}$ Department of Neuroanaesthesia and Neurocritical Care, National Institute of Mental Health and Neuro Sciences, Bangalore, Karnataka, India

${ }^{3}$ Department of Critical Care, Manipal Northside Hospital,

Bangalore, Karnataka, India

J Neuroanaesthesiol Crit Care 2021;8:197-202.
Address for correspondence Kamath Sriganesh, DM, Department of Neuroanaesthesia and Neurocritical Care, National Institute of Mental Health and Neuro Sciences, Bangalore 560029, Karnataka, India (e-mail: drsri23@gmail.com).

\begin{abstract}
Keywords

- therapeutic plasma exchange

- plasma proteins

- neurointensive care unit

Purpose Plasma exchange is one of the recommended therapeutic procedures for autoimmune neurological conditions and involves removal of plasma over multiple sessions for exclusion of autoantibodies responsible for the disease process. This study aimed to evaluate the changes in the concentration of plasma constituents with five cycles of alternate day therapeutic plasma exchange (TPE), identify contributing factors for hypoproteinemia, and examine its impact on clinical outcomes.

Methods This was a single-center, retrospective cohort study involving patients with autoimmune neurological diseases who underwent at least five cycles of TPE in the neurointensive care unit (NICU). Data regarding plasma protein concentrations, serum electrolytes, fluid input/output before and after every TPE cycle and clinical outcomes in terms of duration of ventilation, and NICU and hospital stay were collected from the medical records over a 1 -year period.

Results The levels of plasma proteins (total protein, albumin and globulin) $(p<0.001)$, sodium $(p<0.001)$, calcium $(p<0.001)$, and hemoglobin $(p=0.002)$ declined significantly after TPE. Difference in plasma protein levels before and after TPE did not correlate with durations of mechanical ventilation and hospital and NICU stay. Difference in total protein and globulin correlated negatively with fluid balance and positively with daily protein intake ( $p<0.05$ for both).

Conclusion A significant decrease in plasma proteins and other plasma constituents is seen with TPE. Changes in plasma proteins are related to hemodilution and protein intake. Decrease in plasma proteins did not affect duration of hospital or NICU stay and duration of mechanical ventilation.
\end{abstract}

DOI https://doi.org/ $10.1055 / \mathrm{s}-0041-1734412$ ISSN 2348-0548
(C) 2021. Indian Society of Neuroanaesthesiology and Critical Care. This is an open access article published by Thieme under the terms of the Creative Commons Attribution-NonDerivative-NonCommercial-License, permitting copying and reproduction so long as the original work is given appropriate credit. Contents may not be used for commercial purposes, or adapted, remixed, transformed or built upon. (https://creativecommons.org/licenses/by-nc-nd/4.0/). Thieme Medical and Scientific Publishers Pvt. Ltd. A-12, 2nd Floor, Sector 2, Noida-201301 UP, India 


\section{Introduction}

Therapeutic plasma exchange (TPE) is a procedure performed for immune-mediated neurological diseases such as Guillain-Barre syndrome (GBS) and myasthenia gravis (MG) among others. ${ }^{1,2}$ The goal of TPE is to remove autoantibodies and immune complexes from the plasma to prevent further damage and facilitate reversal of the pathologic process. This procedure involves removal of anticoagulated blood, which is centrifuged to separate the plasma from the cellular elements. The latter is then reinfused along with replacement fluids to maintain intravascular volume and colloid oncotic pressure (COP). The replacement solutions generally used are human albumin 4 to $5 \%, 0.9 \%$ saline, fresh frozen plasma (FFP), hydroxyethyl starch $6 \%$ (HES), gelatin, or dextran 40 , either alone or in combination, each of which has its own benefits and pitfalls. ${ }^{3}$ The American Society for Apheresis provides guidelines for selection of optimal replacement fluid based on the pathophysiology of the underlying disease. ${ }^{4}$

The extracted plasma containing the antibodies that is discarded results in decreased COP from loss of circulating plasma proteins. Other common changes associated with TPE include hemodynamic fluctuations, changes in plasma concentrations of electrolytes and protein-bound drugs, infection, and transfusion reactions. ${ }^{5}$ These secondary changes can affect clinical outcome despite overarching direct benefits from TPE.

The objective of this study was to evaluate the changes in plasma proteins and other plasma constituents during TPE in the neurointensive care unit (NICU) and examine their impact on patient's important clinical outcomes.

\section{Methods}

Study design: This was a retrospective, single-center cohort study conducted in the NICU of a tertiary care neurosciences hospital. The institutional ethics committee approved this study.

Study population: All consecutive adult patients of either sex, aged between 18 and 70 years, admitted to the NICU with a primary neurological diagnosis who underwent TPE were included in the study. We excluded patients who underwent fewer than five cycles of TPE and those undergoing small volume $(<15 \mathrm{~mL} / \mathrm{kg})$ of TPE.

Conduct of TPE: All patients diagnosed with neurological illness and advised TPE for management of their primary disease underwent at least five cycles of TPE every alternate day as per our hospital policy using centrifugation technique with Haemonetics MCS Plus (Haemonetics Corp, Braintee, Massachusetts, United States) apheresis system. Citrate-phosphate-dextrose solution was used for anticoagulation. About $30 \mathrm{~mL} / \mathrm{kg}$ body weight (one plasma volume) of plasma was planned for removal during every cycle performed over a period of 2 to 3 hours in the NICU under close physiological monitoring. In patients with autonomic dysfunction and in the event of hypotension, a lower volume $(20-25 \mathrm{~mL} / \mathrm{kg}$ ) was removed. Intravascular volume during TPE was maintained with administration of $0.9 \%$ saline and HES 6\%. The replacement fluid used after the completion of TPE was a combination of crystalloids and pooled FFP $(\sim 2$ units $)$ in all the patients as per our hospital policy.

Data collection: Data was collected over a period of 1 year from medical and nursing records of the patients. The following data were extracted: volume of plasma removed, daily nutrition (calorie and protein) intake and urine output, type and volume of replacement fluid administered. The biochemical data (serum electrolytes, serum total proteins, serum albumin, serum globulin, hemoglobin, calcium) were recorded prior to the baseline (before the first TPE) and following 12 to 18 hours after each of the five sessions of TPE. Chest radiography during and after TPE was scrutinized for signs of pulmonary edema or congestion. Data regarding outcome measures-duration of ventilation, NICU, and hospital stay-was also collected.

Outcome measures: The primary outcome measures were changes in the total protein and serum albumin after TPE. The secondary outcome measures were changes in serum electrolytes and hemoglobin, and effect of these changes on clinical outcomes-duration of NICU stay, hospital stay, and mechanical ventilation.

Statistical analysis: The data was collated offline on a Microsoft Excel spreadsheet and analyzed using Statistical Package for Social Sciences ver. 17 (IBM, United States). Interval scale variables are described as mean \pm standard deviation and nominal data as percentages. The data was analyzed in three ways-first, individual protein values, electrolytes, and hemoglobin were modeled over time to observe the fixed effect of TPE. Second, day-to-day difference in protein values were calculated and modeled to observe effect of fluid balance and protein intake on plasma protein levels. Fluid balance was calculated by subtracting the urine output and TPE volume from the fluid inputs (crystalloids, colloids, blood products and enteral feeds). Third, difference between maximum and minimum (MMD) of protein values over the TPE days was calculated and correlated with outcome measures (duration of mechanical ventilation, NICU stay and hospital stay). Due to longitudinal design of data and moderately high correlations between data time points, linear mixed effect models were used to model the change of proteins over time and for observing any between subjects' effects or correlations. An autoregressive covariance structure was found to be best fit for individual protein value model and a diagonal covariance matrix for day-to-day difference value model, based on scrutiny of covariance matrix and Akaike's information criterion. Maximum likelihood estimation method was used with random intercepts and slopes incorporated into the model. Residuals of individual models were found to be normally distributed based on visualization of respective histograms. Post-hoc pair wise comparison of time point data was conducted with Bonferroni correction. Correlation of nonlongitudinal variables (MMD and outcome) was conducted using Spearman's correlation due to violation of normality of the outcome variables (positive skew). A $p<0.05$ was taken as level of statistical significance. 


\section{Results}

A total of 51 patients underwent TPE in our NICU during the study period, out of which 37 were diagnosed with GBS and 14 with MG. Eleven patients were excluded from the study due to missing data $(n=8)$ and previous TPE $(n=3)$. Thus, 240 data points ( $n=40,6$ samples per patient including one baseline sample) from 200 TPE sessions (5 sessions/patient) were included in our analysis (-Fig. 1). The TPE was commenced within 7 days of symptom onset in all patients except in one patient with MG.

Descriptive data of the demographics, baseline protein values, outcomes, and MMD protein values are depicted in - Table 1. The average volume of plasma removed was 1160 $\pm 209.76 \mathrm{~mL}$ per session with $500 \mathrm{~mL}$ of $6 \%$ HES used as replacement fluid along with $1048.18 \pm 677.29 \mathrm{~mL}$ of crystalloids and $310.77 \pm 38.82 \mathrm{~mL}$ of FFP over the 24 hours after each TPE session.

\section{Change in Plasma Protein Levels}

There was a statistically significant decrease in total protein, albumin, and globulin concentration during the five sessions of TPE and all values were significantly lower $(p<0.05)$ compared with the corresponding baseline values. The trend of change in the protein levels is depicted in - Fig. 2.

\section{Change in Electrolyte Levels and Hemoglobin}

Similar to protein levels, serum concentrations of sodium, hemoglobin, and calcium decreased significantly following TPE (-Table 2). Serum potassium and chloride also decreased; however, this decrease was not statistically significant.

\section{Correlation of Outcome Variables with MMD}

None of the MMD protein values were found to correlate significantly with any outcome variable (-Table 3 ).

\section{Day-to-Day Difference in Protein Levels}

This analysis was conducted to explore the possibility that the demonstrated decrease in plasma proteins is related to protein intake and hemodilution. Day-to-day difference, rather than actual values were used because, conceptually, the difference in the values would be more directly affected

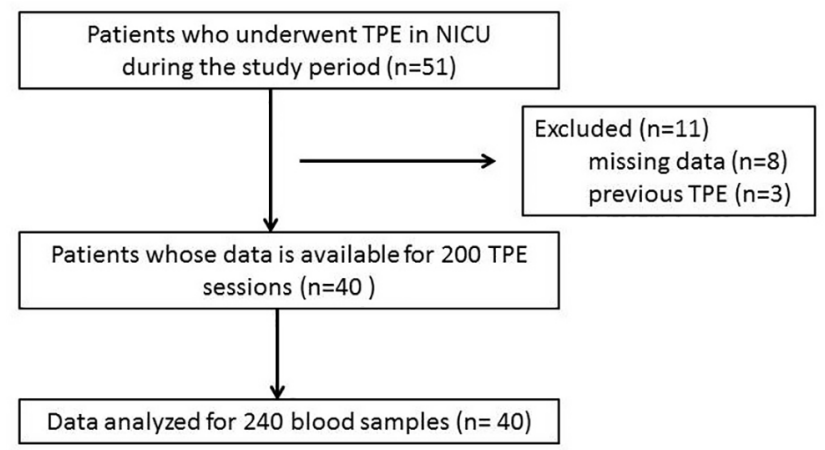

Fig. 1 Flow diagram showing flow of patients in the study. NICU, neurointensive care unit; TPE, therapeutic plasma exchange.
Table 1 Descriptive data of demographics and nonlongitudinal data

\begin{tabular}{|l|l|}
\hline Variable & Descriptive \\
\hline Age $(\mathrm{y})$ & $41.15 \pm 13.43$ \\
\hline Weight $(\mathrm{kg})$ & $54.85 \pm 9.09$ \\
\hline Gender $(\mathrm{F} / \mathrm{M})$ & $13(31) / 27(64.3)$ \\
\hline Diagnosis $(\mathrm{GBS} / \mathrm{MG})$ & $32(76.2) / 8(19)$ \\
\hline Total protein baseline $(\mathrm{g} / \mathrm{dL})$ & $7.38 \pm 7.50$ \\
\hline Albumin baseline $(\mathrm{g} / \mathrm{dL})$ & $3.94 \pm 4.10$ \\
\hline Globulin baseline $(\mathrm{g} / \mathrm{dL})$ & $3.45 \pm 3.30$ \\
\hline MMD total protein $(\mathrm{g} / \mathrm{dL})$ & $2.52 \pm 0.78$ \\
\hline MMD albumin $(\mathrm{g} / \mathrm{dL})$ & $1.43 \pm 0.55$ \\
\hline MMD globulin $(\mathrm{g} / \mathrm{dL})$ & $1.20 \pm 0.51$ \\
\hline Mechanical ventilation duration (d) & $31.50 \pm 33.37$ \\
\hline ICU stay (d) & $37.92 \pm 33.48$ \\
\hline Hospital stay (d) & $53.51 \pm 42.05$ \\
\hline
\end{tabular}

Abbreviations: F, female; GBS, Guillain-Barre syndrome; ICU, intensive care unit; M, male; MG, myasthenia Gravis; MMD, maximum minimum difference.

Note: Values are represented as mean \pm standard deviation, number (percentage).

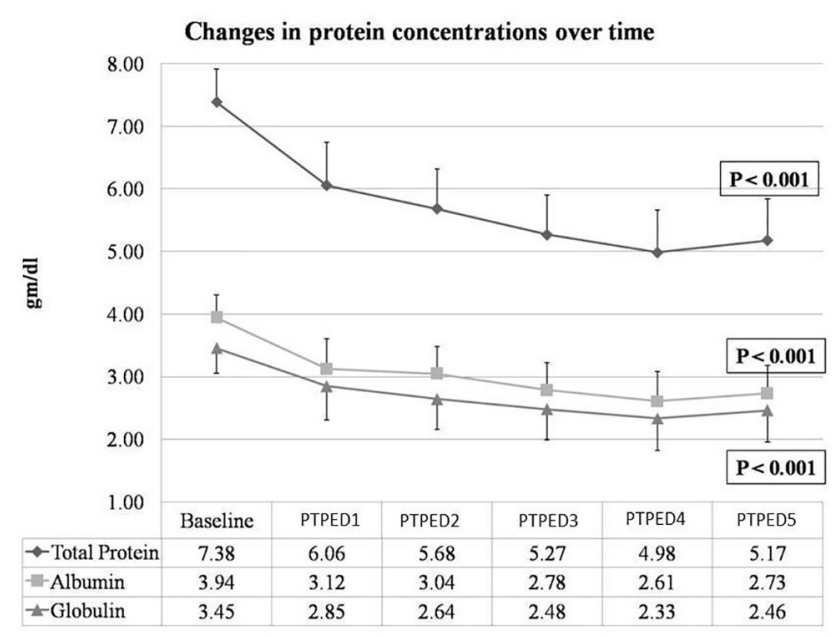

Fig. 2 Trends of change in protein concentration during the five sessions of therapeutic plasma exchange (TPE). post therapeutic plasma exchange day (PTPED)-post-TPE day. Error bars represent 95\% confidence limits (upper and lower limits are equal-only one side is represented). $p<0.05$ level is statistically significant.

by the predictors. It was seen that fluid balance significantly predicted the total protein and globulin difference levels with $1,000 \mathrm{~mL}$ increase in the fluid balance leading to a reduction by a factor of 0.5 and 0.4 , respectively. Similarly, protein intake significantly predicted the protein and globulin difference levels with $1 \mathrm{~g}$ increase in protein intake, leading to an increase by a factor of 0.0116 and 0.0052 , respectively ( - Table $\mathbf{4}$ ).

\section{Discussion}

TPE is recommended as category I (first-line therapy; either standalone or in conjunction with other mode of treatment) 
Table 2 Estimated marginal means (EMM) of serum electrolytes and hemoglobin during therapeutic plasma exchange (TPE)

\begin{tabular}{|c|c|c|c|c|c|}
\hline & & \multirow[t]{2}{*}{ EMM } & \multicolumn{2}{|c|}{ 95\% Confidence Interval } & \multirow[t]{2}{*}{$p$-Value } \\
\hline & & & Lower limit & Upper limit & \\
\hline \multirow[t]{6}{*}{ Sodium (mEq/L) } & Baseline & 135.75 & 134.28 & 137.22 & \multirow[t]{6}{*}{$<0.001$} \\
\hline & PTPED1 & 134.03 & 132.32 & 135.74 & \\
\hline & PTPED2 & 132.55 & 130.97 & 134.13 & \\
\hline & PTPED3 & 131.98 & 130.45 & 133.52 & \\
\hline & PTPED4 & 131.09 & 129.54 & 132.65 & \\
\hline & PTPED5 & 131.76 & 130.16 & 133.36 & \\
\hline \multirow[t]{6}{*}{ Potassium (mEq/L) } & Baseline & 4.10 & 3.93 & 4.28 & \multirow[t]{6}{*}{0.786} \\
\hline & PTPED1 & 3.96 & 3.76 & 4.16 & \\
\hline & PTPED2 & 3.92 & 3.74 & 4.11 & \\
\hline & PTPED3 & 4.03 & 3.85 & 4.21 & \\
\hline & PTPED4 & 3.97 & 3.79 & 4.15 & \\
\hline & PTPED5 & 3.98 & 3.79 & 4.17 & \\
\hline \multirow[t]{6}{*}{ Chloride (mEq/L) } & Baseline & 101.50 & 99.80 & 103.19 & \multirow[t]{6}{*}{0.324} \\
\hline & PTPED1 & 101.29 & 99.33 & 103.26 & \\
\hline & PTPED2 & 99.57 & 97.73 & 101.41 & \\
\hline & PTPED3 & 101.10 & 99.34 & 102.87 & \\
\hline & PTPED4 & 99.43 & 97.65 & 101.22 & \\
\hline & PTPED5 & 99.51 & 97.64 & 101.38 & \\
\hline \multirow[t]{6}{*}{ Calcium (mg/dL) } & Baseline & 9.33 & 9.14 & 9.52 & \multirow[t]{6}{*}{$<0.001$} \\
\hline & PTPED1 & 8.51 & 8.32 & 8.70 & \\
\hline & PTPED2 & 8.40 & 8.17 & 8.62 & \\
\hline & PTPED3 & 8.30 & 8.11 & 8.48 & \\
\hline & PTPED4 & 8.23 & 8.02 & 8.44 & \\
\hline & PTPED5 & 8.06 & 7.81 & 8.31 & \\
\hline \multirow[t]{6}{*}{ Hemoglobin (gm/dL) } & Baseline & 14.02 & 13.29 & 14.75 & \multirow[t]{6}{*}{0.002} \\
\hline & PTPED1 & 13.35 & 12.47 & 14.23 & \\
\hline & PTPED2 & 13.11 & 12.21 & 14.01 & \\
\hline & PTPED3 & 12.43 & 11.54 & 13.31 & \\
\hline & PTPED4 & 11.76 & 10.77 & 12.74 & \\
\hline & PTPED5 & 12.01 & 11.00 & 13.02 & \\
\hline
\end{tabular}

Abbreviation: PTPED, post-therapeutic plasma exchange day.

Note: $p<0.05$ is statistically significant.

Table 3 Coefficients and significance levels for correlation between maximum minimum difference (MMD) and outcome variables

\begin{tabular}{|l|l|l|l|c|}
\hline & & Hospital stay & ICU stay & MV duration \\
\hline \multirow{2}{*}{ Maximum protein change } & Spearman's Rho & 0.118 & 0.106 & 0.152 \\
\cline { 2 - 5 } & $p$-Value & 0.511 & 0.534 & 0.405 \\
\hline \multirow{2}{*}{ Maximum albumin change } & Spearman's Rho & 0.319 & 0.286 & 0.291 \\
\cline { 2 - 5 } & $p$-Value & 0.071 & 0.086 & 0.106 \\
\hline \multirow{2}{*}{ Maximum globulin change } & Spearman's Rho & -0.256 & -0.194 & -0.227 \\
\cline { 2 - 5 } & p-Value & 0.157 & 0.256 & 0.220 \\
\hline
\end{tabular}


Table 4 Effects of fluid balance and protein intake on day-to-day differences in protein levels

\begin{tabular}{|l|l|l|l|l|l|}
\hline Predictor & Outcome & \multirow{2}{*}{ Estimate } & \multicolumn{2}{l|}{ 95\% Confidence interval } & \multirow{2}{*}{$\boldsymbol{p}$-Value } \\
\cline { 3 - 6 } & & & Lower limit & Upper limit & \\
\hline Fluid balance & Protein difference & -0.0005 & -0.0009 & -0.0002 & 0.002 \\
\cline { 2 - 6 } & Albumin difference & -0.0002 & -0.0004 & 0.0001 & 0.147 \\
\cline { 2 - 6 } & Globulin difference & -0.0004 & -0.0006 & -0.0001 & 0.001 \\
\hline Protein intake & Protein difference & 0.0116 & 0.0043 & 0.0190 & 0.003 \\
\cline { 2 - 6 } & Albumin difference & 0.0036 & -0.0012 & 0.0084 & 0.137 \\
\cline { 2 - 6 } & Globulin difference & 0.0052 & 0.0007 & 0.0097 & 0.026 \\
\hline
\end{tabular}

Note: $p<0.05$ is considered as significant.

therapy for GBS as well as MG. ${ }^{6}$ Previous studies on TPE looked largely at long-term outcomes such as median time to recover walking or onset of motor recovery, requirement for mechanical ventilation at 4 weeks, likelihood of full muscle strength recovery or severe motor sequelae, relapse, and death at 1 year. ${ }^{1,2}$

There is very little evidence in literature regarding biochemical and plasma protein changes during TPE in neurological patients with most of studies being in non-English language and from early eighties and nineties, and in nonneurological population such as in patients with rheumatoid arthritis and cancer. ${ }^{7-14}$ The frequency and interval between TPE sessions in earlier studies were different to the current regimens used for GBS and MG. The type of replacement fluid used was also different from the practice adopted in this study. However, most of these studies demonstrated a reduction in the plasma proteins.

Though albumin is the preferred type of replacement fluid, many centers in the developing countries including ours prefer colloid solutions and FFP as replacement fluid in view of the cost. The complications reported with FFP as replacement solution are transfusion reactions, infection, isoimmunization, citrate toxicity, and rarely anaphylactic reactions resulting in laryngeal edema or bronchospasm. ${ }^{3}$ These complications were not seen in our patients.

The decrease in plasma protein concentrations was highest after the first cycle of TPE, with a gradual decline thereafter. This phenomenon has been documented in various studies. Initial studies based on healthy donors have provided ample evidence of rates of reduction in plasma proteins with plasma removal done on a daily/biweekly/weekly/monthly basis for varying time durations. As expected, daily and biweekly plasma donation led to highest reductions in plasma protein levels. ${ }^{15,16}$ However, the same results may not be extrapolatable to bed-ridden NICU patients suffering from neurological disorders. Also, the factors exacerbating or ameliorating this protein decline have not been investigated in contemporary literature. Our findings reveal that TPE performed on alternate days for 5 sessions causes a significant decrease in total protein and globulin levels. This decrease is exacerbated by larger positive fluid balance (hemodilution) and ameliorated by higher dietary protein intake ( - Table 4 ). Although the conceptual basis for this finding is self-explanatory, the absence of effect of fluid and protein intake on albumin levels during the study is discrepant. Albumin synthesis is affected by protein intake, ${ }^{17}$ but the rate of production of albumin is much slower than other proteins. Fractional synthesis rate of total protein was found to be $24.7 \pm 3.1 \%$ /day compared with $5.9 \pm$ $1.2 \% /$ day for albumin in an in-vivo study using radioisotope labeled phenylalanine. ${ }^{18}$ The much slower production might account for the apparent nonassociation between protein intake and albumin levels difference.

The effect of protein depletion on clinical outcomes in neurological patients undergoing TPE has not been studied till date and our data suggests no effect on the length of hospital stay or the duration of mechanical ventilation. This is expected, since the etiogenesis of these outcomes is often multifactorial.

The decrease in serum sodium and calcium levels with TPE is not surprising. Reduction in plasma protein levels is associated with reduction in proximal tubular reabsorption of sodium and can cause hyponatremia. While multiple mechanisms have been proposed for this phenomenon, reduction in extracellular basement membrane back-leak of reabsorbate due to reduction in ambient oncotic pressure is suggested as the most probable cause..$^{19,20}$ Calcium reduction is a very common adverse effect of TPE and is attributed to the use of citrate as an anticoagulant during TPE that chelates the free calcium. ${ }^{21}$

Hemoglobin concentration also showed a significant decrease compared with the baseline following TPE. Literature search reveals insignificant decline or increase in hemoglobin values after single TPE session, and after intensive plasma donation of $1 \mathrm{~L} /$ day for 5 consecutive days. ${ }^{16,22}$ Red blood cell loss in tubing in a single TPE session is $\sim 11 \mathrm{~mL} .^{23}$ To explain the discrepancy with earlier findings, fluid balance was used as a predictor for the day-to-day difference in hemoglobin and it was found that $1000 \mathrm{~mL}$ increase in balance reduced the hemoglobin by a factor of $0.61(p=0.025)$, and thus hemodilution is the likely cause for the observed decrease in hemoglobin in our study. The fluid balance was found to be more negative on day $5(-307.4 \pm 763.6 \mathrm{~mL})$ compared with other days of TPE $(327.3 \pm 707.2,-147.4 \pm 834.9$, $164.3 \pm 634.3,-271.4 \pm 940.2$ for days 1 to 4 , respectively) which explains the increase in hemoglobin, sodium, and protein values on day 5 of TPE compared with day 4 . 


\section{Strengths and Limitations}

This study provides two important findings. Unlike previous studies that informed serum protein changes in healthy volunteers or noncritical and nonneurological patients, our study provides data on plasma protein changes following TPE in critically ill neurological patients in the NICU. Second, our findings of significant reduction in plasma protein levels challenge the current practice of using FFP as a replacement fluid after TPE at many centers in India in place of albumin. Interestingly, despite significant changes in plasma constituents, there was little impact on patient important outcomes. However, this study is not without limitations. The retrospective nature of the study and a small sample size severely limits its generalizability. Also, its external validity is restricted to population following similar TPE practices. Lastly, apart from TPE and resultant changes in the plasma constituents, several other factors during the ICU course can affect clinical outcomes and these were not evaluated in this study. We, however, took into account factors that could influence our primary outcome (changes in plasma proteins) such as protein intake, fluid balance, volume of plasma removed, and replacement fluids.

\section{Conclusion}

TPE results in significant decrease in plasma proteins and other plasma constituents such as sodium, calcium, and hemoglobin. Fluid balance and protein intake predict the decrease in plasma proteins during TPE. However, this decrease during TPE does not affect duration of hospital or NICU stay and duration of mechanical ventilation. Future studies involving larger neurological populations should prospectively explore the significance of changes in plasma proteins with different replacement fluid regimens on clinically important outcomes.

\section{Conflict of Interest}

None declared.

\section{References}

1 Gajdos P, Chevret S, Toyka K. Plasma exchange for myasthenia gravis. Cochrane Database Syst Rev 2002;(4):CD002275

2 Raphaël JC, Chevret S, Hughes RA, Annane D. Plasma exchange for Guillain-Barré syndrome. Cochrane Database Syst Rev 2002;(2). CD001798

3 Nydegger UE. Choice of the replacement fluid during large volume plasma-exchange. Ric Clin Lab 1983;13(1):103-109

4 Szczepiorkowski ZM, Winters JL, Bandarenko N, et al. Apheresis Applications Committee of the American Society for Apheresis. Guidelines on the use of therapeutic apheresis in clinical practice-evidence-based approach from the Apheresis Applications Committee of the American Society for Apheresis. J Clin Apher 2010;25(3):83-177

5 Szczeklik W, Wawrzycka K, Włudarczyk A, et al. Complications in patients treated with plasmapheresis in the intensive care unit. Anaesthesiol Intensive Ther 2013;45(1):7-13
6 Cortese I, Chaudhry V, So YT, Cantor F, Cornblath DR, Rae-Grant A. Evidence-based guideline update: plasmapheresis in neurologic disorders: report of the Therapeutics and Technology Assessment Subcommittee of the American Academy of Neurology. Neurology 2011;76(3):294-300

7 Filomena CA, Filomena AP, Hudock J, Ballas SK. Evaluation of serum immunoglobulins by protein electrophoresis and rate nephelometry before and after therapeutic plasma exchange. Am J Clin Pathol 1992;98(2):243-248

8 Goss GA, Weinstein R. Pentastarch as partial replacement fluid for therapeutic plasma exchange: effect on plasma proteins, adverse events during treatment, and serum ionized calcium. J Clin Apher 1999;14(3):114-121

9 Grgicević D, Pende B. [Effect of long-term plasmapheresis on blood composition. I. Changes in the concentration of total proteins, electrophoretic fractions and immunoglobulins]. Bilt Hematol Transfuz 1981;9(1-3):77-88

10 Movshev BE, Petrova VI, Kalinin NN. [Blood protein-volume indicators in massive plasmapheresis]. Gematol Transfuziol 1992;37(2):12-15

11 Israël L, Edelstein R, McDonald J, Weiss J, Schein P. Immunological and plasma protein changes in cancer patients following a single plasmapheresis. Biomedicine (Paris 1978;28(5):292-297

12 Wahlin A, Grubb A, Holm J, Marklund SL. Effects of plasmapheresis on the plasma concentration of proteins used to monitor the disease process in multiple myeloma. Acta Med Scand 1988;223(3):263-267

13 Lasky LC, Finnerty EP, Genis L, Polesky HF. Protein and colloid osmotic pressure changes with albumin and/or saline replacement during plasma exchange. Transfusion 1984;24(3):256-259

14 Ciszewski TS, Ralston S, Acteson D, Wasi S, Strong SJ. Protein levels and plasmapheresis intensity. Transfus Med 1993;3(1):59-65

15 Shanbrom E, Lundak R, Walford RL. Long-term plasmapheresis: effects on specific plasma proteins. Transfusion 1972;12(3):162-167

16 Kliman A, Carbone PP, Gaydos LA, Freireich EJ. Effects of intensive plasmapheresis on normal blood donors. Blood 1964;23:647-656

17 Kaysen GA, Gambertoglio J, Jimenez I, Jones H, Hutchison FN. Effect of dietary protein intake on albumin homeostasis in nephrotic patients. Kidney Int 1986;29(2):572-577

18 Barle H, Nyberg B, Essén P, et al. The synthesis rates of total liver protein and plasma albumin determined simultaneously in vivo in humans. Hepatology 1997;25(1):154-158

19 Imai M, Kokko JP. Effect of peritubular protein concentration on reabsorption of sodium and water in isolated perfused proximal tubules. J Clin Invest 1972;51(2):314-325

20 Berry CA, Cogan MG. Influence of peritubular protein on solute absorption in the rabbit proximal tubule. A specific effect on $\mathrm{NaCl}$ transport. J Clin Invest 1981;68(2):506-516

21 Weinstein R. Hypocalcemic toxicity and atypical reactions in therapeutic plasma exchange.J Clin Apher 2001;16(4):210-211

22 Evers J, Ehren N, Engelen T, Hansen M, Luethje K, Taborski U. Course of hemoglobin and hematocrit during and after preparatory plasmaphereses without and with infusion of $\mathrm{NaCl} 0.9 \%$ $500 \mathrm{ml}$. Transfus Med Hemother 2014;41(2):114-116

23 Fischer T, Surikova I, Heesen E, Wilms G, Laitinen T, Taborski U. Loss of red cell mass in a plasmapheresis machine: effect of rinsing the disposable tubing with normal saline and reinfusion. Transfus Apheresis Sci 2013;49(1):80-83 